\title{
A Regional Comparison of Factors Affecting Global Sorghum Production: The Case of North America, Asia and Africa's Sahel
}

\author{
Clara W. Mundia ${ }^{1, *}$, Silvia Secchi ${ }^{2} \mathbb{B}$, Kofi Akamani ${ }^{3}$ and Guangxing Wang ${ }^{4}(\mathbb{D}$ \\ 1 Environmental Resources and Policy Program, Southern Illinois University, Carbondale, IL 62901, USA \\ 2 Department of Geographical and Sustainability Sciences, University of Iowa, Iowa City, IA 52242, USA; \\ silvia-secchi@uiowa.edu \\ 3 Department of Forestry, Southern Illinois University, Carbondale, IL 62901, USA; k.akamani@siu.edu \\ 4 Department of Geography and Environmental Resources, Southern Illinois University, \\ Carbondale, IL 62901, USA; gxwang@siu.edu \\ * Correspondence: cmundia@siu.edu
}

Received: 17 February 2019; Accepted: 5 April 2019; Published: 10 April 2019

\begin{abstract}
Understanding the dynamics of food production is critical to improving food security. This is particularly important in regions that rely on subsistence agriculture with little adaptive capacity to climate change. Sorghum plays an important role in food security in some of the poorest parts of the world. This article reviews the literature to identify and examine the major factors affecting sorghum production in three major production regions. Factors were not categorized ex ante but rather determined from the review. Ten major factors were identified as having notable impacts on sorghum production: climate change, population growth/economic development, non-food demand, agricultural inputs, demand for other crops, agricultural resources scarcity, biodiversity, cultural influence, price and armed conflict. This synthesis revealed that (1) multiple factors simultaneously affect sorghum production; (2) the effect of each factor is greatly influenced by the magnitude and certainty of one or more other factors; and, (3) factors differ in relevance and degree with regard to geography. Generally, improved agricultural inputs, population growth/economic development and climate change have substantial influence on sorghum production. However, local dynamics likely go beyond these broad trends and more exhaustive, locally-focused studies are needed for actionable planning purposes.
\end{abstract}

Keywords: food insecurity; global agricultural; sorghum; climate change; adaptation; subsistence production

\section{Introduction}

Food production per capita over recent decades has been rising globally, except in Africa [1]. There is a global rise in demand for crops, and a further demand increase of $59-98 \%$ is expected by 2050 [2]. Yield gaps are a concern. They may be due to extreme weather, crop diversification, amount of inputs used, farm management, and pests and diseases [3].

With population growth, meat consumption is projected to go up by $40 \%$ from 2000 to 2050 [4], as increased affluence will drive up the demand for animal products and other food types (Figure 1). Climate change affects soil and water resources, because higher water temperatures may lead to water quality reduction [5], and flood-plain agriculture might be affected by increasing floods. Water scarcity is expected to affect nearly two billion people by 2025 [4] and become a bigger problem in urban areas with increasing global warming [6]. The Food and Agriculture Organization (FAO) estimates that, by 2050, over three billion tons of cereal will be used for food and non-food purposes [7]. The growth 
of meat consumption and the biofuel market will place an increased demand on grains that are traditionally used for food and feed [4,8]. Crop production for animal feed is more energy wasteful [4], as almost $95 \%$ of food energy available to mankind is lost when diets do not directly utilize cereals (that is, eating meat of animals fed on cereals as opposed to eating cereals directly) [9].

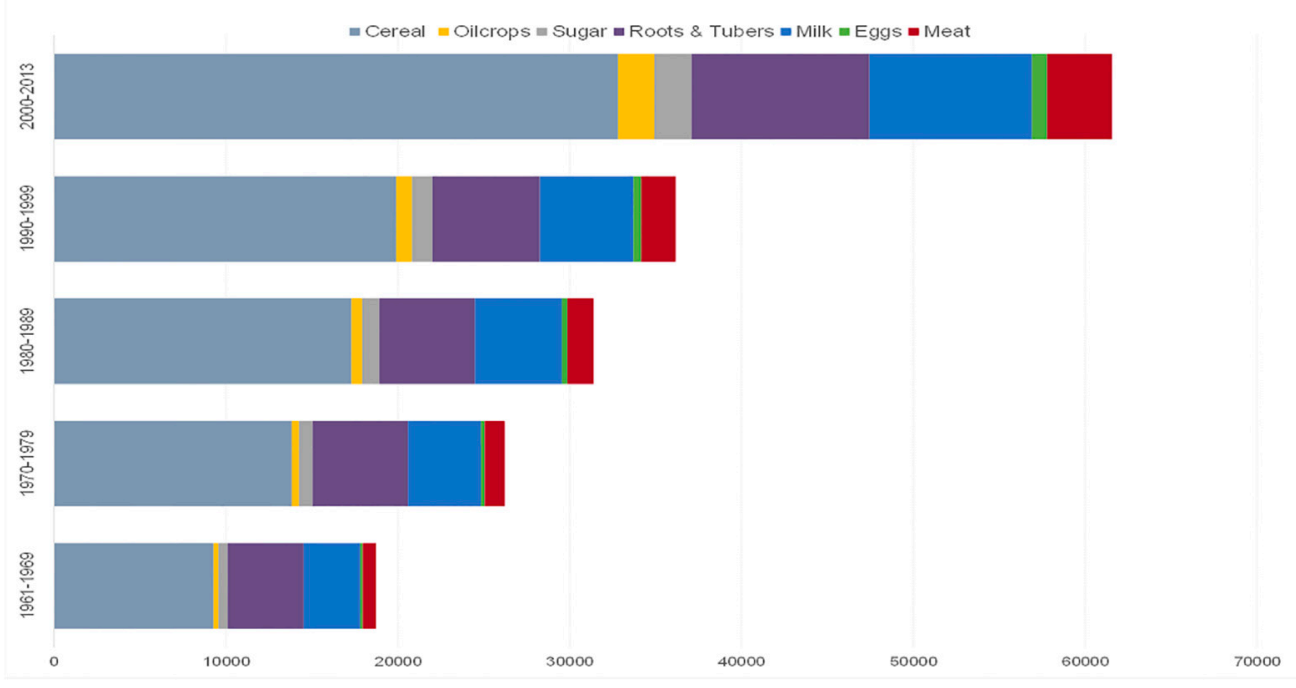

Figure 1. Global average production (in tons) for various major commodities. Source: [10].

There have been impressive successes with respect to improving yields through biotechnology but these triumphs have been limited to rich northern hemisphere countries [11]. Traditional crop varieties have a range of resistance to different pests and diseases, and farmers prefer to grow an aggregate of varieties on their land to combat local pests and diseases [4], but in some regions armed conflict disrupts food production through destruction of land and human fatalities [12]. Low crop production increases food imports [13] and the regions that depend on food imports are largely susceptible to international markets' price fluctuations [14].

The effects of these factors are not globally homogenous and depend on and affect the environmental, socio-economic and political conditions of a particular area. More specifically, food production varies in each of the study regions and is associated with their natural environment, socio-economic resources and population size, and therefore the ability to secure a reliable and abundant food supply depends on those factors [3].

There is no recent comprehensive assessment of factors affecting sorghum production at the global level. The last one, conducted by the International Crops Research Institute for the Semi-arid Tropics (ICRISAT), and the Food and Agriculture Organization of the United Nations, dates to 1996 [15]. There are some studies that take a limited regional focus and look at multiple crops [16,17], particularly in Sub-Saharan Africa and South Asia, due to the challenges these regions face. Previous work on sorghum has focused on those regions as well [18]. Similarly, recent work has considered climate change impacts on a crop [19]. This review more holistically assesses the issues impacting sorghum production. Its approach is broader than one taken by a recent review article on the challenges facing roots, tubers and bananas [20], which aimed at determining where to target investment in order to improve yields. Considering very different production regions in the analysis allows for a more comprehensive assessment of the breadth of challenges sorghum faces and its potential.

Thus, the aim of this review is to examine the existing literature in order to identify the primary drivers of sorghum production in key production regions, and to develop insights into how the dynamics of these factors determine the level of sorghum production in an area. The major regional factors that impact global sorghum production are synthesized for each region and conceptually ranked based on their interrelatedness and effects on sorghum production at the country level. The results 
show that improved agricultural inputs, population growth/economic development and climate change have substantial influence on sorghum production although at varying degrees of certainty depending on the country and/or region.

This study can provide insights on the differences between major global sorghum production systems and describe the influence of various factors on production within countries to better understand the challenges faced in vulnerable parts of the world that are highly dependent on sorghum. Figure 2 outlines the key variables known to play significant roles in global crop production. The results of this assessment can be helpful to policymakers interested in promoting sustainable sorghum production in the future, and to researchers interested in focusing on specific critical factors affecting sorghum production.

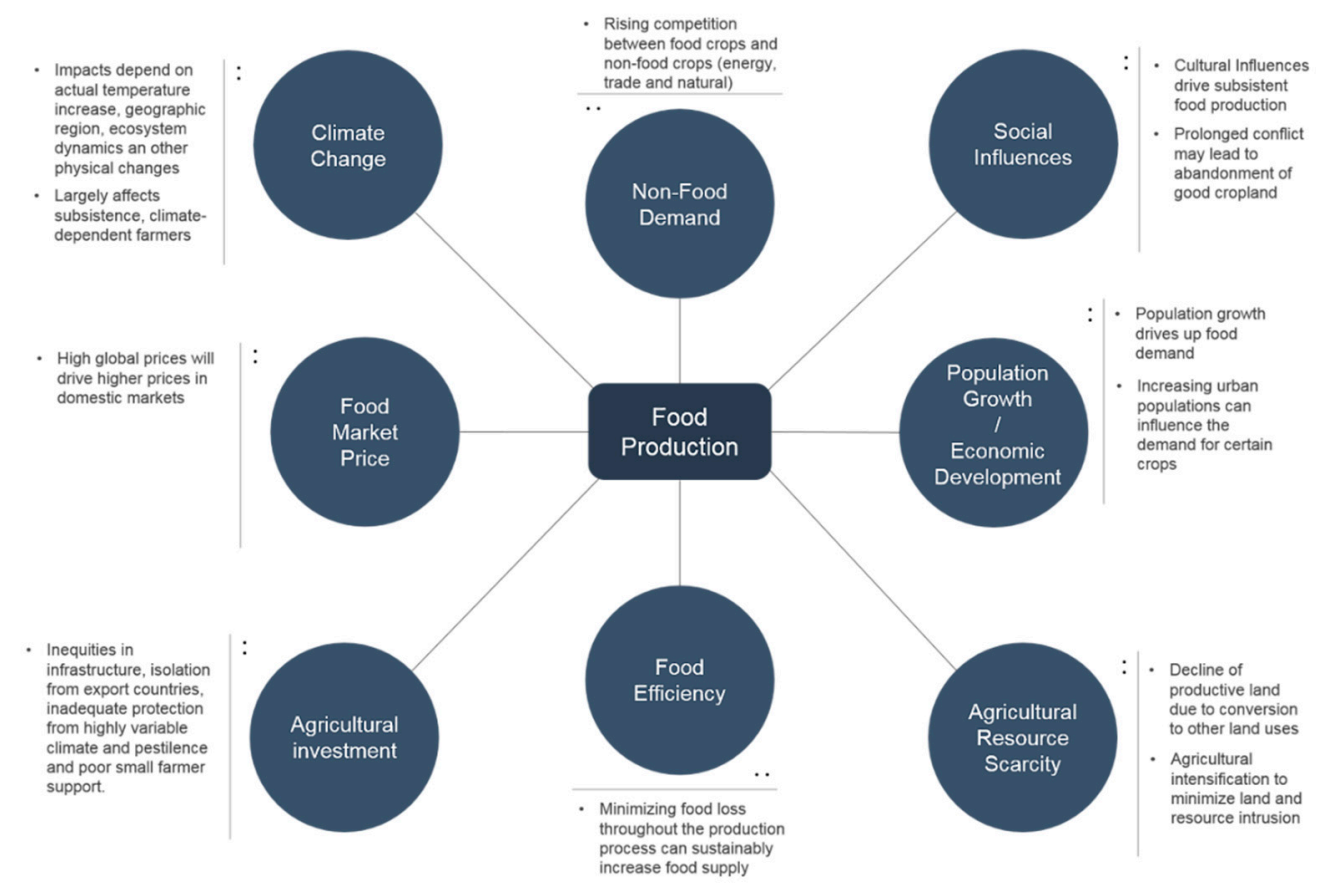

Figure 2. Major factors influencing global food production. Sorghum.

\section{Sorghum}

Sorghum is the fifth most produced grain globally. This two-meter tall plant from the grass family is often grown in regions that have high temperatures and lower rainfall. In wetter regions, its production is lower than that of more lucrative crops such as Oryza sativa (rice) and Zea mays (maize). Sorghum is a particularly essential crop in Africa, second to maize, as the staple grain for millions of people [21]. Although it is mainly consumed as a grain, sorghum is also prepared into a wide variety of other food products such as porridges, breads, lactic and alcoholic beverages, and weaning meals [21].

\subsection{Crop Growth Requirements}

Sorghum is a warm short cycle annual, adapted to withstand higher average temperatures than most other cereal crops [9]. After germination, average temperatures between $24^{\circ} \mathrm{C}$ to $27^{\circ} \mathrm{C}$ are ideal for best yields. Low temperatures can be limiting to sorghum growth [22] and most plants will die when exposed to below freezing temperatures [23]. Sorghum is often grown in regions that get between 350-700 mm of precipitation annually [21]. As a predominantly rain-fed crop, its yield depends largely on its drought resistance. The ideal soil moisture during germination ranges between $25 \%$ and $50 \%$ of field capacity [24] and the sorghum plant can survive flooding events as it is more tolerant of wet soils $[21,23]$. Sorghum is often grown in shallow to medium deep or light to medium-textured soils and/or medium to deep soils of high-water capacity after the rainy reason [22]. 
Sorghum yield is partly determined by the varieties of cultivars and the cultural practices of the region. For example, over many generations, most African sorghum farmers have selected varieties that cater to their environmental conditions and food preferences, thus the actual number of distinct traditional sorghums on the continent could range into the thousands [25]. Since sorghum is not only a food crop, varieties are chosen to meet specific uses. For example, in some stress areas low-yield, high resistant varieties are grown for straw in addition to grain [26] while cultivars with low amounts of tannins are preferred as staple grains [9]. When increased production is required, farmers often extend into marginal lands as opposed to intensive production of the existing acreage.

\subsection{Sorghum Diversity}

Sorghum is a very genetically diverse crop both in cultivated and wild species [27], with the Sorghum bicolor ssp. bicolor as the majority bearer of commercial varieties. Sorghum's five races are known as bicolor, guinea, caudatum, kafir and durra. The greatest variation within the sorghum genus is found in Ethiopia-Sudan (northeast Africa) where it is likely to have originated [28] (Figure 3).

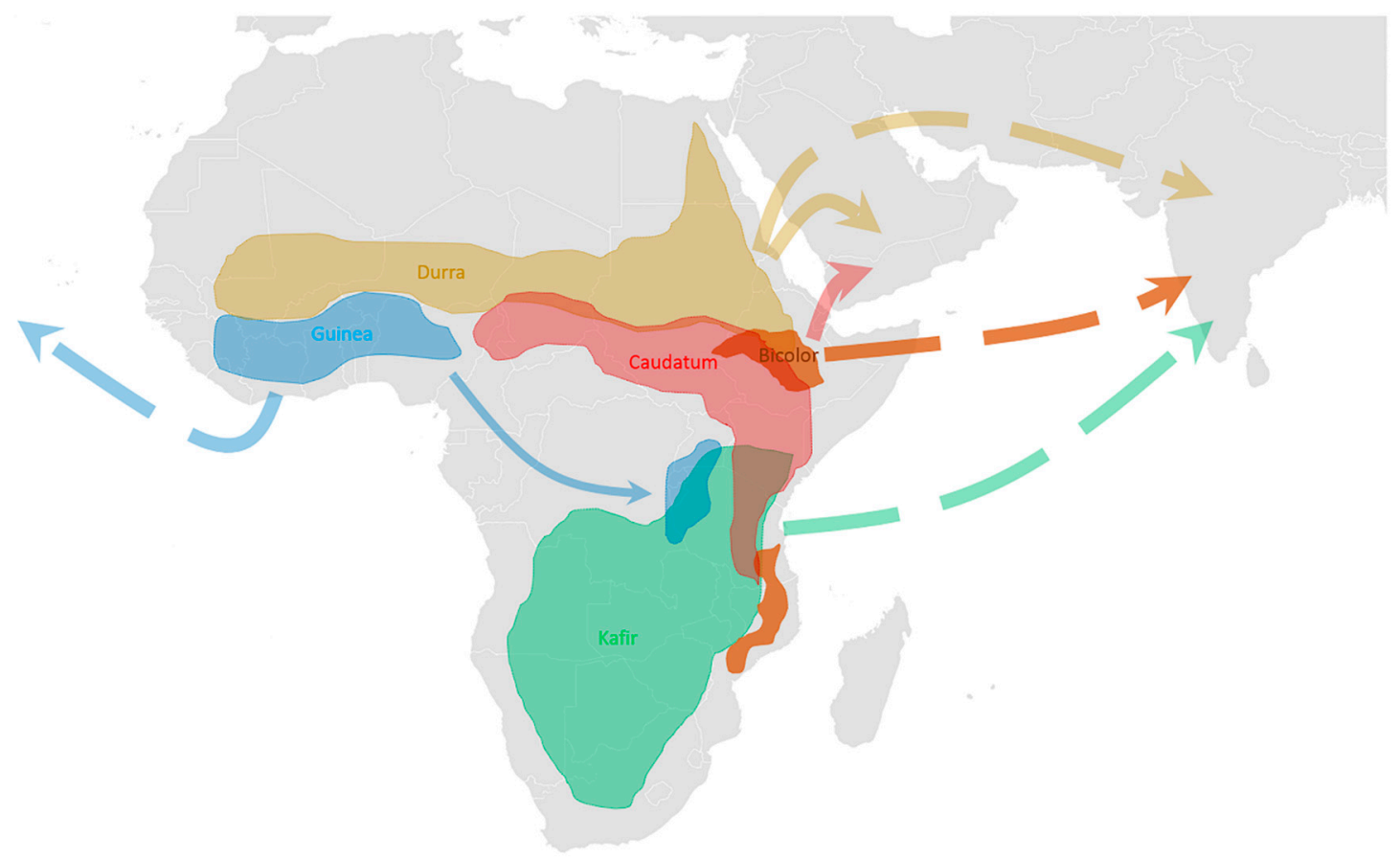

Figure 3. The origin and spread of the races of Sorghum bicolor in Africa and Asia. Source: Map digitized from narrative in $[28,29]$.

Durra is the oldest and most drought-tolerant of the five races, originating in Ethiopia and later evolved in West Asia, where it remained widespread in semiarid areas [25,30]. In Africa, durra is found in the region from the Horn of Africa/East Sahel to the West. Guinea sorghum is widely adapted in the wetter West Africa (western Nigeria to Senegal) and the caudatum race is associated with the Chari-Nile speaking Africans of the eastern savannah [30] and largely extends from eastern Nigeria, Chad and western Sudan [25]. Kafir is mainly grown in areas from Tanzania to South Africa. The high variation in sorghum is evident in the fact that over 18 subspecies were at one time recognized by scientists [25].

Sorghum diversified according to local ecological conditions and the desired crop uses through selection and hybridization with wild sorghum [28,31]. Due to the highly variable climate in the production regions, adaptable varieties were either developed or imported from other areas, which brought about inter-variety crossbreeding at the local level [32]. In a comparison study over a 26-year period (1976-2003), researchers found that sorghum genetic diversity in Niger has undergone 
minimal losses with variation driven by the cultural identity of the farmers [32]. In another similar study done in southern Somalia, it was found that the high genetic diversity in 20 accessions of landraces sampled was quite possibly due to the deliberate actions of farmers to satisfy their needs [33]. Both studies suggest that farmer practices play a large part in the dynamics of genetic diversity of crops [34,35], particularly in regions where subsistence farming is practiced.

Sorghum varieties in the Sahel have often been used as ex-situ collections to promote variability in farms. A study showed that for many of the major subsistence crops, genetic diversity is being maintained on farms that utilize traditional landraces and wild varieties [35]. There is a large unexploited variability in sorghum genetics in relationship to plant type, grain type, adaptability and yield capacity. Sorghum's genetic potential has been overlooked and it is far less developed than that of other major crops [25]. This will likely change, as many of the known global breadbaskets, rice lands and corn belts, may become more suitable for sorghum production due to climate change [25].

\subsection{Global Sorghum Production}

Sorghum is grown all over the world (Figure 4). In Asia, the major growing nations are China, Pakistan, India, Korea and Thailand. In Sub-Saharan Africa, sorghum has significant presence in 38 countries. It is grown in the United States and Mexico in North America and Argentina, Nicaragua, Peru, Uruguay, Honduras, Brazil, Colombia, El Salvador, Guatemala, Haiti and Venezuela in South America. It is also grown in the European countries of France, Italy, Spain, Romania and Albania [36] and produced in Australia. More than $90 \%$ of total global sorghum harvested areas are in Africa and Asia [36,37], with Africa accounting for $61 \%$ of the area and $41 \%$ of production and Asia accounting for $22 \%$ of the area and $18 \%$ of production [37]. Over 61 million metric tons of sorghum were produced in 2013 with the top producers (in amount) being the United States, Nigeria, Mexico, India and Sudan. The majority of sorghum production was in Africa (41\%), followed by the Americas (38\%) and then Asia (18\%) (Table 1). Remarkably, Israel, Jordan, France and Italy have historically had the highest yields on relativity small cultivated areas [36].

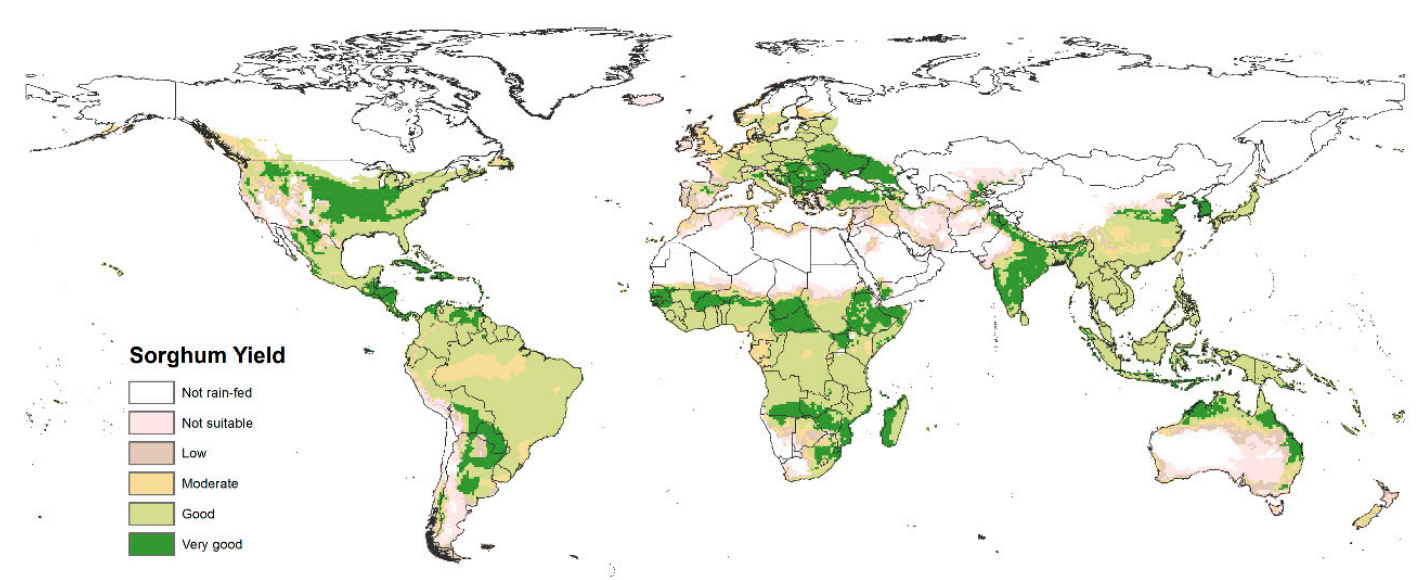

Figure 4. Global sorghum output under rain-fed conditions for the year 2010. Source: [38]. 
Table 1. Global sorghum production by tonnage (in millions) per region.

\begin{tabular}{cccccc}
\hline Region & $\mathbf{2 0 0 0}$ & $\mathbf{2 0 0 5}$ & $\mathbf{2 0 1 0}$ & $\mathbf{2 0 1 3}$ & $\mathbf{2 0 1 5}$ \\
\hline World & 55.8 & 59.6 & 60.0 & 61.3 & 63.5 \\
Africa & 18.4 & 24.8 & 24.7 & 25.7 & 24.8 \\
N. C. America & 18.0 & 15.7 & 15.9 & 16.4 & 17.2 \\
South America & 4.9 & 5.3 & 6.2 & 6.8 & 5.5 \\
Asia & 11.3 & 18.2 & 10.5 & 8.7 & 8.0 \\
Europe & 0.7 & 0.5 & 0.7 & 1.1 & 0.9 \\
Oceania incl. Australia & 2.1 & 2.0 & 1.6 & 2.2 & 2.1 \\
\hline \multicolumn{5}{c}{ Source: $[10,39]}$.
\end{tabular}

Sorghum can thrive in both temperate and tropical climates as it has a high photosynthetic efficiency [25]. In the drier ranges, it is commonly replaced by pearl millet (Africa, India) or foxtail millet (India, China), and in the wetter ranges by maize [30]. Sorghum has a short maturity period and the highest food production per unit of energy spent [25]. It can be grown under different conditions (rain-fed, irrigated, seedling transplanting or rationing), making it suitable for both subsistence and commercial farming. Post-harvest, its versatility allows the whole plant to be consumed/utilized for a variety of uses (broom-making, firewood, animal feed, fuel, food) and prepared in a number of ways (boiled, cracked, malted, baked and popped) [25].

Global sorghum production increased by 25\% between the 1960s and 1980s [37]. In the 1980s, two thirds of production was from developed countries. Production in Asia has been increasing. By 2008, Asia accounted for one quarter of global production [37]. Since the 1980s, sorghum-cultivated areas have remained constant, save for a slight decline in developed countries [37]. In the last half decade, globally, sorghum cultivated areas have been reduced by $5 \%$ [40] down to 44 million hectares between 2006 and 2008 [32]. Importantly, developed countries account for only $8 \%$ of the area but are responsible for $22 \%$ of global production due to high yields [37].

\section{Sorghum Production Challenges}

Globally, sorghum still remains below its yield potential. The reasons lie in its traditional reputation as a coarse grain used primarily as animal feed and dubbed 'the poor man's food', reserved for low income populations [25]. Sorghum is difficult to process into food-quality form, unlike other cereals. Although its nutrient composition does not largely differ from maize or Triticum aestivum (wheat), brown sorghum has tannins that inhibit the assimilation of nutrients during digestion and the crop has general low digestibility [25].

Due to market deregulation, price support policies for sorghum have often been greatly reduced or just simply eliminated in favor of subsidies for maize, rice and wheat [37]. Between the 1980s to the mid-2000s, sorghum production declined largely due to policy measures in Asia, North America and Europe affecting both supply and consumer preferences [37]. The global sorghum price is mainly determined by the demand for sorghum feed. As the largest feed exporter, the United States dictates the global price trends [37]. In the 1980s, the establishment of hybrids and new drought resistant varieties increased yields and the export price of sorghum declined. Briefly in 1984, the price increased when sorghum demand went up as a result of the trade ban on maize from the former U.S.S.R.; but in the following years, up until 2000, the price continued to decline due to decreased demand in United States, the former U.S.S.R. and China because of changes in policy, wheat surpluses and increases in India's production [37]. After 2000, prices rose as a result of the growing biofuel industry, the demand for sorghum in the manufacture of bio-ethanol and the shortage of maize feed grain in Europe.

Because sorghum is often grown as a subsistence crop, its local price can be relatively insulated from the world price. There is evidence, however, that in urban markets there is a long run relationship between world and domestic consumer prices, but domestic prices do not adjust fast to changes in world prices [41]. Thus, subsistence production countries are shielded from global price shocks, but it may make them more vulnerable to droughts and other climate change impacts. This appears to have 
been the case in Niger in 2006, for example [42], and may explain why sorghum prices were highly volatile in Africa and central America between 2000 and 2012 [43]. Sorghum is one of the few crops for which price volatility has increased in recent years [44]. The literature on impacts of climate change on sorghum yields indicates that there will be substantial yield reductions and increased volatility from West Africa and Botswana to India [45-47]. It is likely that sorghum production will face intensified challenges in the future, and populations who depend on sorghum as a staple will have to confront increased food insecurity.

\section{Sorghum Production: A Regional Assessment}

Africa, North America and Asia are the top sorghum producing regions (see Table 1). In Asia, production is dominated by China and India, while in North America, the United States and Mexico are the top producers. In Africa, Nigeria and Sudan are leading producers of sorghum. This review focused on Nigeria and Burkina Faso (ranked first and third in African production, respectively) that partly lie in the west Sahel, a region well known to suffer from food insecurity. An understanding of the characteristics of sorghum production in this part of the Sahel relative to other strong sorghum producing regions can provide valuable insights on what factors to consider to improve production and secure food supply.

\subsection{Sorghum in Asia}

The introduction of sorghum to Asia is not well documented, though the crop is believed to have first reached India late in the second century and then spread to China, most likely through the Mongol conquest [30]. Sorghum production in Asia was stagnant at 20 million tons from the 1960s to the early 1990s [48]. Although sorghum yields had increased, they were offset by the decline in cultivated areas which shifted to more economically valuable crops like rice, maize and wheat [48]. In mainland Asia, sorghum is used in India, Burma, Pakistan and China for the production of roti (flatbread), porridge, starch, and as input in alcoholic beer manufacturing. However, its use as animal fodder has rapidly increased over the last five decades as the demand of animal products has expanded in the region [48]. Additionally, the growing urban populations' demands for fruits and vegetables have begun to have impacts on sorghum cultivation areas [30]. Current yields of sorghum in Asia are closer to global averages, with cultivation concentrated within India and China [37]. Global production increased by $51 \%$ from 1960 to 2009, mostly through improvements in breeding technology. Overall, though, Asia's fraction of the total global production has decreased [40].

\subsubsection{India}

In 2000, India was the second largest producer of sorghum (after the United States), holding the largest cultivated area [49], but the country now ranks 5th behind Mexico, Sudan and Nigeria [50]. Sorghum is the country's third most important crop, and is grown on 11 million hectares, mainly in the semiarid regions [49]. It is believed that sorghum was introduced from East Africa (Somalia to Mozambique) by $1000 \mathrm{BC}$ on board dhows as seamen provisions [25]. Currently, India accounts for over $70 \%$ of the total sorghum production on the continent and has four times the cultivated area of all other Asian countries combined [48], yet it has yields below the Asian average [51].

The sorghum race grown in India is the drought tolerant durra, and improved varieties have been developed over the decades [25]. Sorghum is cultivated during the rainy kharif (June-October) and post-rainy rabi (September-January) seasons with over $90 \%$ of production purely rain-fed [48]. Kharif sorghum, a yellow grain, is grown on over $53 \%$ of the production area and it accounts for $63 \%$ of production. Kharif sorghum is high yielding, though it generally has a lower market price than the white grain, rabi, that dries under warmer weather and has a higher quality but lower yield [30]. Kharif is mostly grown in the states of Maharashtra, Karnataka and Madhya Pradesh, but, due to rain-induced molding, it tends to be less profitable than the rabi [49]. Grain mold significantly reduces both yield and quality of sorghum and is greatly influenced by environmental factors such as rainfall, 
temperature, $\mathrm{pH}$, humidity and the type of storage structure [52]. Most of sorghum production uses minimal agricultural inputs [30]. Only a small amount of sorghum is irrigated, usually forage sorghum in the semiarid temperate states of Punjab, Haryana and western Uttar Pradesh [37]. Sorghum's major advantage in India is its ability to withstand the black-cotton soils (vertisols) that are clayey and often difficult to farm due to the highly fluctuating water tables [25,53].

Cultivated areas declined annually by $3 \%$ since the 1980 s as sorghum was replaced by sunflower, soybeans and cotton [37]. Affluence drew populations to consume more wheat and rice, whose extended keeping quality and easy preparation were preferred [54]. The low demand for sorghum in traditional uses is reflected in its low market price relative to other crops, and it is only in a few select rural areas where sorghum demand increases with increased income [48], indicating that sorghum is generally considered an inferior good in India.

Vegetarianism is widespread in India, however there is a significant majority $(74 \%)$ of the population who eats poultry and mutton. With the increase in purchasing power and population growth, meat consumption and feed demand are forecast to keep increasing [49]. Although research has found advantages in using sorghum in poultry feed, the grain is still considered a second-best option in animal feed due to its traditional reputation, low palatability and digestibility, damage-risk during storage, and limited seasonal availability. Thus, sorghum is often used when maize is rationed or too expensive [49]. In the urban and peri-urban areas, the demand for fodder by the dairy industry is high and farmers often sell sorghum stalks as animal feed [30].

In India, the price of feed sorghum is $5-15 \%$ lower than that of maize, and it has been suggested that increasing this difference could boost its attractiveness in the feed industry. However, the selling price of rainy season sorghum is often dictated by the quality of the grain, which can decrease from deterioration during storage [37,49]. Producer prices for sorghum are higher in India than anywhere else in the world as consumers are willing to pay for higher quality post-rainy season grain [37].

Alcohol production in the country creates a demand for damaged grains as the alcohol distillation technology can utilize blackened sorghum grains unlike the feed and food sectors. Sorghum alcohol generates the least pollution and, unlike molasses-based batches, produces sulphate-free alcohol. Also, byproducts can be used as animal feed [49]. To a smaller degree, sorghum is used in starch production, however, this tends to happen only when there is a shortage of maize. Maize is preferred as sorghum is abrasive and causes grinding machinery wear and tear [49].

\subsubsection{China}

China is the eighth global producer. It uses sorghum for human food (30\%), animal feed and alcoholic beverages $[48,50,54,55]$. Sorghum was introduced through the spreading of Indian cultivars, during the silkworm trade or directly from the eastern coast of Africa by returning Chinese seamen [25,54]. China follows India in cultivated area and production. Between the 1930s and 1950s, sorghum was grown as a traditional cereal on 10 million hectares, but the production area drastically declined to about 2 million hectares by 1990 [48] and then further to 0.6 million hectares by 2008 [37]. However, production has remained constant due to the impressive increases in yields that are nearly four times those of India.

Since the 1970s, there has been a shift away from sorghum production for human consumption, which decreased by two million tons in 1990. This corresponded to a decrease in sorghum area, and area increases in the more profitable maize [37]. Instead, sorghum has gained popularity as animal fodder, and in recent years the country has invested in research on improved cultivars for this purpose [48]. Still, in the semiarid and arid rural areas, sorghum remains a major part of the population's diet [48]. China is also a major exporter of sorghum grain [48]. The major commercial use of sorghum in China has been the production of a popular alcoholic beverage, Baijiu [30]. 


\subsection{Sorghum in North America}

The major growing countries in the continent are the United States and Mexico. Sorghum was officially introduced in the mid-nineteenth century as 'guinea corn' that arrived from West Africa during the slave trade [54]. Sorghum production is primarily targeted towards animal feed. The United States and Mexico are the major consumers of feed sorghum [30], accounting for $80 \%$ of total global production.

\subsubsection{United States}

Benjamin Franklin, who cultivated sorghum seeds off an imported broom, was the first to record the use of sorghum in the United States [56]. In the nineteenth century, 'broomcorn' was utilized as a raw material in broom manufacturing. Sorghum was first grown on the eastern coast, spreading to the west coast by 1900 [25]. Sweet sorghum was introduced in the mid-1800s and used to produce syrup, but due to the rise of corn syrup, production of sorghum syrup never became large-scale. Sorghum syrup today is still used in rural villages in the south [57]. In the early 1900s, sudangrass (a type of sorghum grown primarily as fodder) was introduced and used for animal feed throughout the country [25]. The United States is the most significant producer of this crop, accounting for $17 \%$ of world production on only $6 \%$ of global cultivated area [37]. The grain is mainly grown in the variable, low-rainfall plains in the central and southern parts of the country, in Texas, Missouri, Nebraska and Kansas, and most of it is exported to Mexico and Japan [25,53].

In the sorghum belt (South Dakota to South Texas), sorghum is mainly grown in dry areas on ultisols and mollisols soil types [53]. In Texas, sorghum is grown in drylands under irrigation as an annual often rotated with cotton, corn, soybean, wheat and peanuts. In the 1940s, the southern states accounted for nearly two thirds of the country's production [57]. Sorghum area declined starting in the 1980s, due to changes in agricultural support policies that favored drought-tolerant maize varieties over sorghum [37]. Surprisingly, yield improvements in sorghum have outweighed other cereals in the United States [25]. Any further increases in sorghum production in the United States will depend on the introduction of new varieties tolerant of early and mid-season cold temperatures that cause cold stress during emergence [58].

Currently, nearly $40 \%$ of domestic sorghum is used in the production of ethanol [56]. Sorghum is also grown for commercial seed production for the domestic and export markets [59].

\subsubsection{Mexico}

Mexico ranks second in global sorghum production [50]. Sorghum is the third largest crop in area and value after maize and cotton, contributing to $10 \%$ of total production [59]. The changes associated with sorghum production have been termed the country's second 'Green Revolution' [25]. This revolution came in the form of a 2772 percent increase in sorghum production between the late 1950s to early 1980s with over 1.5 million hectares planted [25]. Prior to 1953, there was no record of the existence of sorghum in Mexico. Sorghum's minimal water requirement compared to maize and wheat mean the crop is a good fit in the large dry lands of Mexico [25]. Sorghum is mainly grown during the spring-summer season (April to September), in the dry states of Tamaulipas, Guanajuato, Sinaloa, Michoacán and Jalisco [59]. Sorghum is cheaper to produce, has higher yields, and is more reliable under low rainfall events than maize [25].

Sorghum was initially used as animal feed in Mexico due to the higher cost of maize, but now there is a growing demand for food-quality sorghum varieties to make tortillas (a staple round flat bread), breakfast cereal, starch and European barley beers [25,57]. In the 1980s, the implementation of the North American Free Trade Agreement caused increased maize imports by Mexican livestock producers and this discouraged sorghum imports from the United States [60]. In the early 1990s, sorghum feed use declined as more livestock producers began to use maize as animal feed. By the mid-1990s, however, this trend was reversed in part due to Mexico's reduced support for maize and 
water constraints in maize irrigation. In recent years, the fast-growing population has increased the demand for sorghum, and both domestic production and imports have increased [60].

\subsection{Sorghum in the Sahel}

Sorghum was introduced through the expansion of barter trade in North Africa after it was domesticated in the Sahel by 2000 BC and it became a staple. In this region, the main race is the guinea, due to its diversity and adaptability to local challenging environmental conditions [31]. Urban dwellers within the Sahel have begun to introduce more imported rice into their diets due to its affordability and fast cooking property, yet, in the rural areas, sorghum remains a substantial part of the diet [54]. Another major challenge is the infestation of the parasitic weed, striga, and bird and pest intrusion pre-harvest [30]. Pest and disease control require greater agricultural inputs, such as herbicides or improved seed varieties, and since sorghum is mostly grown as a subsistence crop, this is not an affordable option $[30,37,53]$. Sorghum culture in this region is done on sandy oxisols and alfisols that are deficient in nitrogen and phosphorous and low in organic matter. Generally, in Africa, sorghum is consumed as porridge or fermented beverages [25].

\subsubsection{Nigeria}

Despite uncertainty over the location of first domestication of sorghum, researchers agree that early varieties of sorghum were present in West Africa, where it is commonly referred to as guinea corn, by the medieval period [61]. Nigeria accounts for up to $40 \%$ of total sorghum production in Africa (70\% in West Africa) and is the third largest producer after the United States and India $[62,63]$. Sorghum is the most important cereal food in the northern states, contributing to about $73 \%$ of total caloric and $52 \%$ of the per capita protein intake [64,65]. Crops are grown under farming systems with unimproved inputs and traditional tools [66], with irrigation employed along the main river systems [67]. Besides food, sorghum is used as livestock feed, house thatching and in the beverage and baking industries in Nigeria [66].

Sorghum production in Nigeria surpasses all other crops [66] and has the potential to be viable and profitable [64]. Production is negatively affected by climate challenges and institutionally-induced price volatility [65]. The shrinking of Lake Chad over the past decades has put a strain on the livelihood of 40 million people whose food and income depend on subsistence farming [68]. Sorghum farmers have been faced with trading regulations that raise fees and restrict access to agricultural inputs, high transportation costs and export bans $[65,69]$. This is further exacerbated by recurring militant insurrections which continue to affect sorghum production in the dominant cultivation region of northeastern Nigeria [68].

In 2009 , nearly $70 \%$ of sorghum was used domestically as food and $30 \%$ as animal feed, while less than $1 \%$ was formally traded internationally. Commercial sorghum production was driven by industries such as beverage (malt and beer) and biofuel [70]. Sorghum and corn were exclusively used in beer manufacturing, even after the ban on barley imports was lifted in 1999. However, the popularity of corn and soybeans resulted in declining sorghum production across all production regions [63]. Nigeria has been self-sufficient in the past, but recently, sorghum imports from the United States have been necessary to meet local demand in the northeastern areas because of conflict [71]. Farmers are still optimistic because of increasing prices, rising demand from regional markets in Niger, Chad, Mali and Burkina Faso and from the beverage industry, and the committed input support of private sector industrial consumers [71].

In the north, informal cross border trading is known to exist between Nigeria, Chad and Niger, with Niger and Chad largely on the receiving end [63,70]. Traditional transportation through donkey, pick-up vans and trucks is typical. This method is expensive, but due to poor road conditions, limited rail service and route bottlenecks, there are no alternatives [72]. A lack of farmer-to-market connectedness and the self-consumer nature of production have led to a poorly developed sorghum value chain [70]. 


\subsubsection{Burkina Faso}

Burkina Faso is the continent's third top producer of sorghum (after Nigeria and Sudan) [73]. Nearly $90 \%$ of the population depends on rain-fed cereal production, $44 \%$ of which is sorghum [74]. Notably, Burkina Faso's cereal production grew by one million tons between 1986 and 2005 and the country was the first among Sahelian countries to have a cereal surplus, and the most successful in agricultural development [75]. Sorghum is primarily grown in the Guinea-savannah and Sudano-savannah regions [74]. Most of sorghum production comes from Boucle du Mouhoun and northern regions, small percentages come from the Hautes Bassins, and the Central Western and North-Central regions [76]. Although breeding strategies have been successful, most of the sorghum produced is from traditional cultivars, which are more adapted to the rainfall variability of the region [74].

White sorghum is used for food products while red sorghum is used primarily to brew the local beer, dolo, and is only used in food preparation if white sorghum is in shortage [77]. Sorghum is frequently found away from dwellings on high-altitude fields or areas with low fertility and is often intercropped with cowpeas, sesame and groundnuts [78] to conserve soil moisture and reduce risk of total crop failure. Mineral fertilizers are also commonly used to maintain soil fertility [77]. Due to low variable rainfall and high evapotranspiration rates, soil fertility is a major agricultural constraint. Soils are highly weathered, have poor physical structure, and low clay and organic and nutrient content $[77,79]$. Thus, crop yields are soil-limited in Burkina Faso due to the level of soil infertility and its low capacity to regenerate [78].

Although it is profitable to village and regional wholesalers, less than $50 \%$ of sorghum is sold in the markets [80]. Burkina Faso and Niger are predicted to have rapid population growth, especially in water-stressed areas, and this future rise in demand is a significant concern [79]. However, unlike in Niger, it is feared that variety erosion is in fact occurring in Mali and Burkina Faso largely due to competition from cash crops [81].

\section{Discussion}

Ten main factors were identified to have notable impact on sorghum production within the major sorghum-producing regions considered in this review: climate change, agricultural input, population/economic growth, biodiversity, agricultural resource scarcity, other crop demand, price, non-food demand, cultural influence and armed conflict.

These factors varied in their importance in different regions. In order to synthesize these factors and conceptualize their differences, Figure 5 was developed. It shows a comparison of each factor's influence on sorghum production in the six countries within the three topmost sorghum producing regions. A graph for each country shows each of the ten factors as colored bars whose height represents their magnitude of influence as very low (VL), low (L), medium (M) and high (H). This ranking was developed from assessments made from the previous sections' description of sorghum growth requirements and accounts of sorghum production characteristics within each country. 


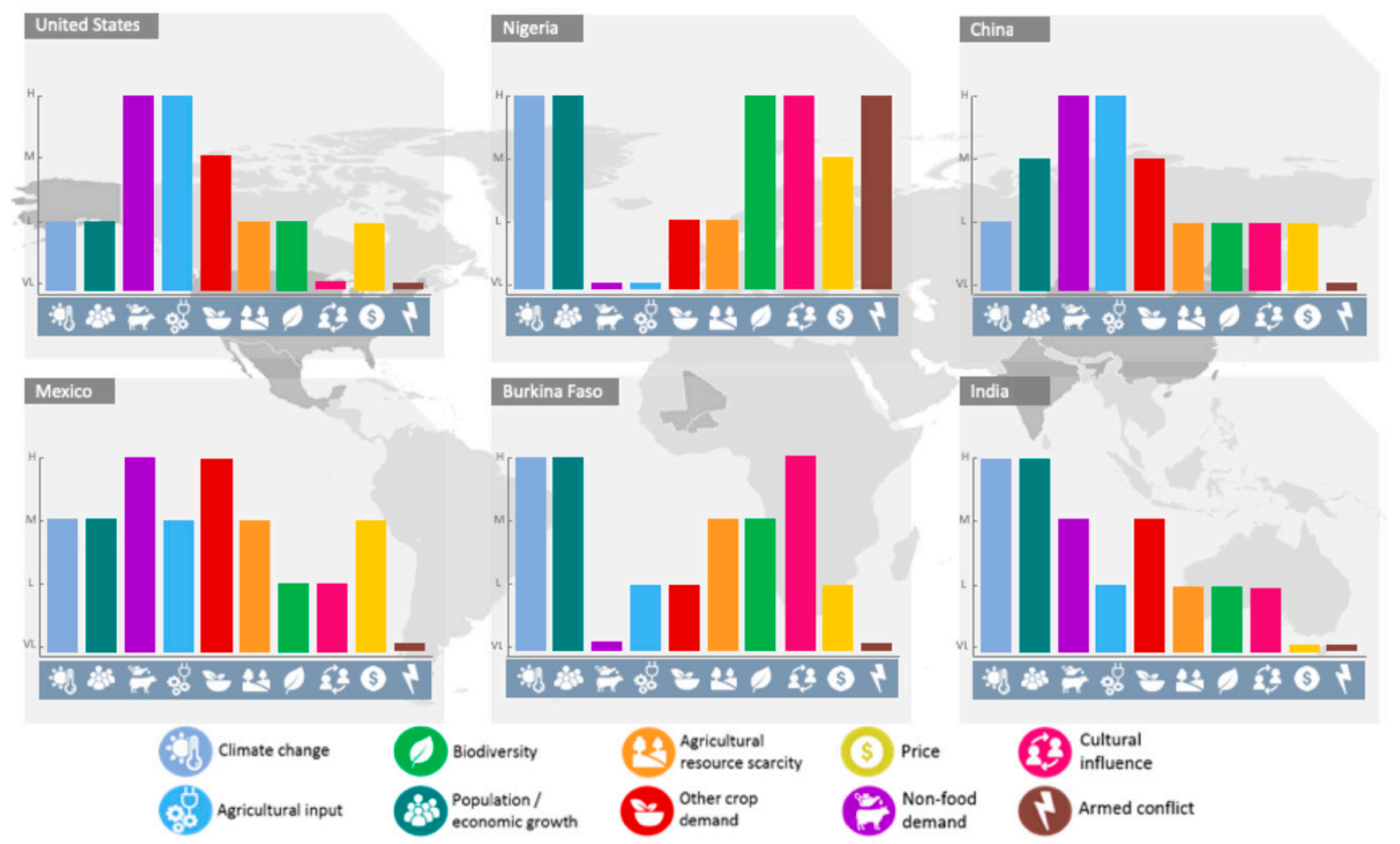

Figure 5. A graphical representation of the level of influence of various factors on sorghum production in each of the major producing countries within the top producing regions. Each factor is represented by a color bar, whose height corresponds to the level of influence where: VL is very low, L is low, M is medium and $\mathrm{H}$ is high.

\subsection{Influence of Factors}

The effects of climate change, a relevant factor within all regions, are often greatly mitigated by investments in agricultural inputs such as improved crop varieties, irrigation and machinery. Where rain-fed production is more prominent and / or there is a minimal or complete lack of agricultural inputs, climate dependency and lack of adaptive capacity cause a higher influence of this factor.

The importance of population and economic growth varies with the type of production and sorghum grown. Subsistence production, where human consumption is the dominant end-use, is the most directly impacted by this factor. Conversely, for sorghum feed production, the influence of this factor lies in changes in urban dietary preferences that expand or reduce consumption of cereal and/or animal products. This factor's influence would be largely variable in emerging market economies, and it would be dependent on the dynamics of their respective growth patterns.

Regions with relatively high use of sorghum in meat, alcohol and biofuel production are significantly influenced by non-food demand. Dietary preferences and food policies are likely to affect this factor's influence as trends towards more meat-based diets and alternative fuel crops (e.g., maize) increase. Surges in non-food demands may be trivial to overall sorghum production when the bulk of production targets direct human consumption.

Investment in well-established, improved agricultural inputs generates high sorghum yields and has historically driven the substantial difference between the productivity of developed and developing countries. Traditional domestic production suffers from low yields due to climate and natural resource dependency. Inputs in the form of favorable policies, trading governance, and robust markets may cause variability in the impact of this factor in countries that do not just produce sorghum for domestic production but are involved in trading it.

As sorghum is often treated as secondary to other grains, it is susceptible to changes in the demand and supply of these crops. Sorghum production is strongly impacted by surpluses in maize, a preferred crop both as feed and in ethanol production. This consequently affects exports. 
Increases in fruit/vegetable consumption generate similar effects. However, the harsh climate and lack of agricultural inputs mean low competition from other crops in low-cost subsistence sorghum production areas.

Improved agricultural inputs can help counteract the effects of land and resource scarcity and reduce the impact of this factor. In developing regions, there have been attempts to introduce intercropping and fertilizer applications. Drying of the sorghum grown in semi-arid lands may force increased imports and reduce domestic sorghum production. Rapidly growing urban areas in emergent economies will begin to encroach on available cultivated areas, pushing agricultural lands into more marginal areas, further perpetuating resource scarcity.

Biodiversity is a relatively less prominent factor for improved sorghum varieties. In subsistence production areas, however, spatially and genetically increased diversity among traditional sorghum cultivars improves yield, helps mitigate the impacts of a variable climate and caters to different use preferences. High biodiversity in sorghum alone does not offset other negative impacts and can have an overall minimal influence. Culture is only relevant in dominantly subsistence sorghum production areas. Outside of these, the extent of the influence of culture is largely unknown.

The market price of sorghum is a relevant factor among countries that export the crop on an international scale and is in part dictated by the policy-induced price changes of major exporters. Where domestic formal and informal trading of sorghum is dominant, global price is a less influential factor. Lastly, the effect of conflict plays a negligible role at a global scale, but in a selection of developing regions it is an occasional concern, and in the drier regions central to sorghum production its effects can be devastating.

\subsection{Overall Ranking of Factors}

Among all the examined factors, improved agricultural inputs, population and economic growth and climate change appear to be the most influential globally. Improved agricultural inputs increase sorghum productivity and can even lessen the negative effects of other factors. In the rural areas where subsistence sorghum is grown, population growth will mostly likely drive an increase in demand and therefore production, while for urban populations demand may decrease as food preferences change. Climate change is a threat, mostly to countries that rely on rain-fed farming and lack adequate adaptive capacity, for example via agricultural inputs. It is important to remember that localized factors such as culture and even conflict cannot be ignored when considering strategies to improve production in low yield areas.

The findings of this global review are similar to the findings of previous local research. According to Omoro [82], traditional production methods, low technological adoption, environmental constraints and policy impediments are major reasons behind low sorghum production among small-scale farmers in Kenya. In a study on the climate-resilience of sorghum cultivars, Tack et al. [83] suggested the need to genetically increase heat resilience in sorghum varieties as a response to extreme heat events in the United States. For poorer countries like Malawi, agricultural inputs such as fertilizer and post-harvest (residual) management can generate economic benefits even with increases in future climate variability [84]. Traditional inputs will not be a long-term solution for sorghum food supply if populations in those countries continue to rapidly grow, and technological advances are needed.

\section{Conclusions}

The review approach taken in this study confirms that multiple factors affect sorghum production, and that these factors interact with each other and present regional differences. At the global scale, two major traits of sorghum production are: (i) there is very high variability in yields, and (ii) great similarities exist among countries at equivalent developmental stages. It may be decades before sorghum attains a more prominent status as an international cash crop and it will likely continue to be grown on subsistence farms. It is clear that the dynamics of the major factors affecting global sorghum production go beyond this global assessment and more exhaustive, locally-focused reviews 
would be needed for actionable planning purposes. Understanding the roles played by more regional factors-such as biodiversity, culture and conflict-in each sorghum-growing region is essential and requires more locally-focused investigations.

Specifically, more detailed investigations that consider local and global agricultural and trading policies as well as market structure could provide further insight on regional production trends. Also, there is some uncertainty in the level of a factor's influence that stems from its interactions with other known or unknown factors. This uncertainty is more likely to be captured through a quantitative approach at the local level and should be encouraged in future analyses. An assessment of the critical factors affecting sorghum production in localized settings is the first step in addressing the challenge of how to modify and improve critical factors to secure satisfactory production particularly in the more vulnerable regions.

From a policy perspective, the main implications of the study are that (i) since sorghum production is more volatile in areas that have less capacity to adapt to climate change, and since sorghum yields will be affected by climate change, policy interventions should target more at-risk areas; (ii) the interventions would have to be place-specific, consider the factors discussed in this review, and avoid a top-down approach. Possible activities would include facilitating seed exchanges, developing new varieties, and introducing crop insurance schemes; (iii) since in large parts of the world, sorghum is a staple of the poorest of the poor, monitoring of sorghum production may helpful as an early indicator of food insecurity, and ensure that interventions to avoid malnutrition and famine occur promptly.

Future research directions include more micro and meso-scale studies, to better understand issues such as households' division of labor in sorghum production, and the role communities play in promoting or hindering production and spreading races and varieties.

Author Contributions: Conceptualization, C.W.M. and S.S.; methodology, C.W.M., K.A. and S.S.; writing-original draft preparation, C.W.M.; writing-review and editing, S.S., K.A. and G.W.; visualization, C.W.M.; supervision, G.W. All authors discussed the results and commented on the manuscript.

Funding: This research received no external funding.

Acknowledgments: The authors would like to thank Prof. Robert W. Snow who provided insight and expertise that greatly assisted the development of this manuscript.

Conflicts of Interest: The authors declare no conflict of interest.

\section{References}

1. FAO. FAO Statistical Pocketbook: World Food and Agriculture 2018; Food and Agriculture Organization of the United Nations: Rome, Italy, 2018; Available online: http:/ /www.fao.org/3/CA1796EN/ca1796en.pdf (accessed on 16 March 2019).

2. Elferink, M.; Schierhorn, F. Global Demand for Food Is Rising. Can We Meet It; Harvard Business Review: Boston, MA, USA, 2016; Available online: https:/ /hbr.org/2016/04/global-demand-for-food-is-rising-canwe-meet-it (accessed on 16 March 2019).

3. Penning de Vries, F.W.T.; Rabbinge, R.; Groot, J.J.R. Potential and Attainable Food Production and Food Security in Different Regions. Philos. Trans. R. Soc. Lond. B Biol. Sci. 1997, 352, 917-928. [CrossRef]

4. Nellemann, C.M.M.; Manders, T.; Eickout, B.; Svihus, B.; Prins, A.G.; Kaltenborn, B.P. (Eds.) The Environmental Food Crisis-The Environment's Role in Averting Future Food Crises; A UNEP Rapid Response Assessment; UNEP/Earthprint: Arendal, Norway, 2009; Available online: https://www.gwp.org/globalassets/global/toolbox/references/the-environmental-crisis.-theenvironments-role-in-averting-future-food-crises-unep-2009.pdf (accessed on 15 December 2015).

5. Raleigh, C.; Urdal, H. Climate Change, Environmental Degradation and Armed Conflict. Political Geogr. 2007, 26, 674-694. [CrossRef] 
6. IPCC. Summary for Policymakers. In Climate Change 2014: Impacts, Adaptation and Vulnerability: Regional Aspects. Part A: Global and Sectoral Aspects; Field, C.B., Barros, V.R., Dokken, D.J., Mach, K.J., Mastrandrea, M.D., Bilir, T.E., Chatterjee, M., Ebi, K.L., Estrada, Y.O., Genova, R.C., et al., Eds.; Contribution of Working Group II to the Fifth Assessment Report of the Intergovernmental Panel on Climate Change; Cambridge University Press: Cambridge, UK, 2014.

7. Alexandratos, N.; Bruinsma, J. World Agriculture Towards 2030/2050: The 2012 Revision; ESA Working Paper No. 12-03; FAO: Rome, Italy, 2012; Available online: http:/ / www.fao.org/fileadmin/templates/esa/Global_ persepctives/world_ag_2030_50_2012_rev.pdf (accessed on 24 November 2015).

8. Naylor, R.L.; Liska, A.J.; Burke, M.B.; Falcon, W.P.; Gaskell, J.C.; Rozelle, S.D.; Cassman, K.G. The Ripple Effect: Biofuels, Food Security, and the Environment. Environ. Sci. Policy Sustain. Dev. 2007, 49, 30-43. [CrossRef]

9. Hall, A.E. Crop Responses to Environment, 1st ed.; CRC Press: Boca Raton, FL, USA, 2000; ISBN 9780429126543-CAT\#KE81975.

10. FAOSTAT Database Collections, FAO. Available online: http://www.fao.org/faostat/en/\#data (accessed on 15 December 2015).

11. Thornton, P.K.; Jones, P.G.; Ericksen, P.J.; Challinor, A.J. Agriculture and Food Systems in Sub-Saharan Africa in a 4 C+ World. Philos. Trans. A Math. Phys. Eng. Sci. 2011, 369, 117-136. [CrossRef] [PubMed]

12. Messer, E. Rising Food Prices, Social Mobilizations, and Violence: Conceptual Issues in Understanding and Responding to the Connections Linking Hunger and Conflict. NAPA Bull. 2009, 32, 12-22. [CrossRef]

13. Mortimore, M.J.; Adams, W.M. Farmer Adaptation, Change and 'Crisis' in the Sahel. Glob. Environ. Chang. 2001, 11, 49-57. [CrossRef]

14. FAO; WFP; IFAD. The State of Food Insecurity in the World 2013: The Multiple Dimension of Food Security; FAO: Rome, Italy, 2013; Available online: http://www.fao.org/3/a-i3434e.pdf (accessed on 20 December 2015).

15. International Crops Research Institute for the Semi-Arid Tropics; Food and Agriculture Organization of the United Nations. The World Sorghum and Millet Economies: Facts, Trends and Outlook; Food and Agriculture Organization: Rome, Italy, 1996; Available online: http:/ / oar.icrisat.org/1024/ (accessed on 21 March 2019).

16. Adhikari, U.; Nejadhashemi, A.P.; Woznicki, S.A. Climate change and eastern Africa: A review of impact on major crops. Food Energy Secur. 2015, 4, 110-132. [CrossRef]

17. Reynolds, T.W.; Waddington, S.R.; Anderson, C.L.; Chew, A.; True, Z.; Cullen, A. Environmental Impacts and Constraints Associated with the Production of Major Food Crops in Sub-Saharan Africa and South Asia. Food Secur. 2015, 7, 795-822. [CrossRef]

18. Slakie, E.; Reynolds, T.; Chew, A.; Gebrekidan, B.; Anderson, C.L.; Cullen, A.; Gugerty, M.K. Agriculture-Environment Series: Sorghum/Millet Systems At-A-Glance, EPAR Brief No. 21; Evans School Policy Analysis and Research (EPAR), University of Washington: Seattle, WA, USA, 2013; Available online: https:/ / pdfs.semanticscholar.org/717a/3561264d19087731dad54436186aee4912d5.pdf (accessed on 21 March 2019).

19. Raymundo, R.; Asseng, S.; Robertson, R.; Petsakos, A.; Hoogenboom, G.; Quiroz, R.; Hareau, G.; Wolf, J. Climate Change Impact on Global Potato Production. Eur. J Agron. 2018, 100, 87-98. [CrossRef]

20. Petsakos, A.; Prager, S.D.; Gonzalez, C.E.; Gama, A.C.; Sulser, T.B.; Gbegbelegbe, S.; Kikulwe, E.; Hareau, G. Understanding the Consequences of Changes in the Production Frontiers for Roots, Tubers and Bananas. Glob. Food Secur. 2019, 20, 180-188. [CrossRef]

21. Food Security Department. Sorghum: Post-harvest Operations. In INPhO-Post-Harvest Compendium; Mejia, D., Lewis, B., Eds.; Natural Resources Institution, University of Greenwich: London, UK, 1999; Available online: http:/ / www.fao.org/3/a-ax443e.pdf (accessed on 15 December 2015).

22. Carter, P.R.; Hicks, D.R.; Oplinger, E.S.; Doll, J.D.; Bundy, L.G.; Schuler, R.T.; Holmes, B.J. Grain Sorghum (Milo). In Alternative Field Crops Manual; University of Wisconsin Cooperative or Extension Service: Madison, WI, USA, 1989.

23. Du Plessis, J. Sorghum Production; South Africa: Department of Agriculture: Pretoria, South Africa, 2003; Available online: https://www.nda.agric.za/docs/Infopaks/FieldCrops_Sorghum.pdf (accessed on 15 December 2015).

24. Fawusi, M.O.A.; Agboola, A.A. Soil Moisture Requirements for Germination of Sorghum, Millet, Tomato, and Celosia. Agron. J. 1980, 72, 353-357. [CrossRef] 
25. National Research Council. Lost Crops of Africa: Grains; Ruskin, F.R., Ed.; National Academies Press: Washington, DC, USA, 1996; Volume 1, ISBN 978-0-309-17689-7.

26. Batello, C.; Marzot, M.; Touré, A.H.; Kenmore, P.E. The Future is an Ancient Lake: Traditional Knowledge, Biodiversity and Genetic Resources for Food and Agriculture in Lake Chad Basin Ecosystems; FAO: Rome, Italy, 2004.

27. Iqbal, A.; Sadia, B.; Khan, A.I.; Awan, F.S.; Kainth, R.A.; Sadaqat, H.A. Biodiversity in the Sorghum (Sorghum bicolor L. Moench) Germplasm of Pakistan. Genet. Mol. Res. 2010, 9, 756-764. [CrossRef] [PubMed]

28. OECD. Consensus Document on the Biology of Sorghum (Sorghum bicolor L. Moench), 62nd ed.; Organization for Economic Co-operation and Development: Paris, France, 2016.

29. Olsen, K.M. One Gene's Shattering Effects. Nat. Genet. 2012, 44, 616-617. [CrossRef] [PubMed]

30. Kiple, K.F. The Cambridge World History of Food; Cambridge University Press: Cambridge, UK, 2000.

31. Vom Brocke, K.; Trouche, G.; Weltzien, E.; Barro-Kondombo, C.P.; Gozé, E.; Chantereau, J. Participatory Variety Development for Sorghum in Burkina Faso: Farmers' Selection and Farmers' Criteria. Field Crop Res. 2010, 119, 183-194. [CrossRef]

32. Deu, M.; Sagnard, F.; Chantereau, J.; Calatayud, C.; Vigouroux, Y.; Pham, J.L.; Mariac, C.; Kapran, I.; Mamadou, A.; Gérard, B.; et al. Spatio-Temporal Dynamics of Genetic Diversity in Sorghum bicolor in Niger. Theor. Appl. Genet. 2010, 120, 1301-1313. [CrossRef] [PubMed]

33. Manzelli, M.; Benedettelli, S.; Vecchio, V. Agro-biodiversity in Subsistence Farming Systems of South Somalia-Collection and Agronomic Assessment of Somali Sorghum (Sorghum bicolor L. Moench) Germplasm. Tropicultura 2006, 24, 213-220.

34. Labeyrie, V.; Deu, M.; Barnaud, A.; Calatayud, C.; Buiron, M.; Wambugu, P.; Manel, S.; Glaszmann, J.C.; Leclerc, C. Influence of Ethnolinguistic Diversity on the Sorghum Genetic Patterns in Subsistence Farming Systems in Eastern Kenya. PLoS ONE 2014, 9, e92178. [CrossRef]

35. Vigouroux, Y.; Barnaud, A.; Scarcelli, N.; Thuillet, A.C. Biodiversity, Evolution and Adaptation of Cultivated Crops. C. R. Biol. 2011, 334, 450-457. [CrossRef]

36. Deb, U.K.; Bantilan, M.C.S.; Hash, C.T.; Ndjeunga, J. Adoption of Improved Sorghum Cultivars. In Sorghum Genetic Enhancement: Research Process, Dissemination and Impacts; International Crops Research Institute for the Semi-Arid Tropics: Patancheru, India, 2004.

37. Bhagavatula, S.; Rao, P.P.; Basavaraj, G.; Nagaraj, N. Sorghum and Millet Economies in Asia-Facts, Trends and Outlook; International Crops Research Institute for the Semi-Arid Tropics: Patancheru, India, 2013.

38. Sorghum Annual Yield; Potsdam Institute for Climate Impact Research (PIK): Potsdam, Germany, 2006.

39. USDA. World Agricultural Production; Circular Series WAP 1-16; USDA: Washington, DC, USA, 2016.

40. Nedumaran, S.; Abinaya, P.; Bantilan, M.C.S. Sorghum and Millets Futures in Asia Under Changing Socio-Economic and Climate Scenarios. In Socioeconomics Discussion Paper Series Number 2; International Crops Research Institute for the Semi-Arid Tropics: Patancheru, India, 2013.

41. Baquedano, F.G.; Liefert, W.M. Market Integration and Price Transmission in Consumer Markets of Developing Countries. Food Policy 2014, 44, 103-114. [CrossRef]

42. Rapsomanikis, G. Price Transmission and Volatility Spillovers in Food Markets. In Safeguarding Food Security in Volatile Global Markets; Prakash, A., Ed.; Food and Agriculture Organization: Rome, Italy, 2011; pp. 149-168.

43. Kornher, L.; Kalkuhl, M. Food Price Volatility in Developing Countries and its Determinants. Q. J. Int. Agric. 2013, 52, 277-308.

44. Sarris, A. Options for developing countries to deal with global food commodity market volatility. Paper Presented at the Annual World Bank Conference on Development Economics (ABCDE), Paris, France, 30 May-1 June 2011.

45. Chipanshi, A.; Chanda, R.; Totolo, O. Vulnerability Assessment of the Maize and Sorghum Crops to Climate Change in Botswana. Clim. Chang. 2003, 61, 339-360. [CrossRef]

46. Srivastava, A.; Kumar, S.N.; Aggarwal, P.K. Assessment on Vulnerability of Sorghum to Climate Change in India. Agr. Ecosyst. Environ. 2010, 138, 160-169. [CrossRef]

47. Sultan, B.; Guan, K.; Kouressy, M.; Biasutti, M.; Piani, C.; Hammer, G.; McLean, G.; Lobell, D.B. Robust Features of Future Climate Change Impacts on Sorghum Yields in West Africa. Environ. Res. Lett. 2014, 9 , 104006. [CrossRef] 
48. Kelley, T.G.; Parthasarathy Rao, P.; Singh, R.P. Trends in Sorghum Production and Utilization in Asia; International Crops Research Institute for the Semi-Arid Tropics: Andhra Pradesh, India, 1992.

49. Kleih, U.; Ravi, S.B.; Rao, B.D.; Yoganand, B. Industrial Utilization of Sorghum in India. J. SAT Agric. Res. 2007, 3, 1-38. Available online: http:/ / ejournal.icrisat.org/mpii/v3i1/impi1.pdf (accessed on 15 December 2015).

50. USDA. World Agricultural Production; Circular Series WAP 3-19; USDA: Washington, DC, USA, 2019.

51. Sivakumar, M.V.K.; Huda, A.K.S.; Virmani, S.M. Physical environment of sorghum-and millet-growing areas in south Asia. In Agrometeorology of Sorghum and Millet in the Semi-Arid Tropics, Proceedings of the International Symposium, Patancheru, India, 15-20 November 1982; International Crops Research Institute for the Semi-Arid Tropics: Patancheru, India, 1984.

52. Ratnavathi, C.V.; Komala, V.V.; Vijaykumar, B.S.; Das, I.K.; Patil, J.V. Fumonisin B1 Contamination in Kharik Grain Sorghum in India. Qual. Assur. Saf. Crop. Foods 2012, 4, 146. [CrossRef]

53. Krishna, K.R. Agroecosystems: Soils, Climate, Crops, Nutrient Dynamics and Productivity, 1st ed.; Apple Academic Press: Oakville, ON, Canada, 2013; ISBN 9781926895482-CAT\#N10851.

54. FAO. Sorghum and Millets in Human Nutrition; FAO Food and Nutrition Series, No 27; FAO: Rome, Italy, 1995; pp. 16-19.

55. Iqbal, M.A.; Iqbal, A. Overview on Sorghum for Food, Feed, Forage and Fodder: Opportunities and Problems in Pakistan's Perspectives. Am. Eurasian J. Agric. Environ. Sci. 2015, 15, 1818-1826. [CrossRef]

56. National Sorghum Producers. Sorghum 101. Available online: http://sorghumgrowers.com/sorghum-101/ (accessed on 25 December 2015).

57. Sandhill Farms. Sorghum FAQs. Available online: http://www.sandhillfarm.org/sorghum_FAQs.php (accessed on 15 December 2015).

58. Reddy, B.V.S.; Ashok Kumar, A.; Sharma, H.C.; Rao, P.S.; Blummel, M.; Ravinder Reddy, C.; Sharma, R.; Deshpande, S.P.; Mazumdar, S.D.; Dinakaran, E. Sorghum Improvement (1980-2010): Status and Way Forward. J. SAT Agric. Res. 2012, 10,1-14.

59. Leslie, J.F. (Ed.) Sorghum and Millets diseases. In World Agriculture, 1st ed.; John Wiley \& Sons: New York, NY, USA, 2008; ISBN 978-0-470-38470-1.

60. USDA. Effects of North American Free Trade Agreement on Agriculture and the Rural Economy; Zahniser, S., Link, J.E., Eds.; WRS-02-1; Electronic Outlook Report from the Economic Research Service, USDA: Washington, DC, USA, 2002.

61. Norman, M.J.T.; Pearson, C.J.; Searle, P.G.E. The Ecology of Tropical Food Crops, 2nd ed.; Cambridge University Press: Cambridge, UK, 1995.

62. FAO. Food Security Assessment in the Northeastern States of Nigeria; FAO Rapid Seed System Assessment Report; FAO: Rome, Italy, 2016; pp. 16-64.

63. USDA. Nigeria Grain and Feed Annual; Nicely, R., Nzeka, U., Eds.; Gain Report; Global Agriculture Information Network, USDA Foreign Agricultural Service: Lagos, Nigeria, 2014.

64. Aduba, J.J.; Mohammed, B.T.; Jilasaya, I.; Ozumba, I.C. An Economic Analysis of Sorghum Production among Sorghum Farmers in Kwara State Nigeria. Glob. J. Curr. Res. Monogr. 2013, 1, 116-123.

65. Odozi, J.C. Cross Border Trade in Grain between Nigeria and Neighbouring Niger: Risk Management Assessment Along Sokoto Illela-Konni Border Land. Cogent Econ. Financ. 2015, 3, 1029250. [CrossRef]

66. Baiyegunhi, L.J.S.; Fraser, G.C.G. Profitability in Sorghum Production in Three Villages of Kaduna State Nigeria. J. Appl. Sci. Res. 2009, 5, 1685-1691.

67. Blench, R. A History of Agriculture in Northeastern Nigeria. In L'Homme et le milieu végétal dans le Bassin du Lac Tchad; ORSTOM: Paris, France, 1997; pp. 69-112.

68. FAO. Lake Chad Basin Crises: Response Strategy (2017-2019): Mitigating the Impact of the Crisis and Strengthening the Resilience and Food Security of Conflict-Affected Communities; FAO: Rome, Italy, 2017; pp. 1-12.

69. Colman, D.; Young, T. Principles of Agricultural Economics: Markets and Prices in Less Developed Countries; Cambridge University Press: Cambridge, UK, 1989.

70. Gourichon, H. Analysis of Incentives and Disincentives for Sorghum in Nigeria. In Technical Notes Series; MAFAP, FAO: Rome, Italy, 2013.

71. Scott, R.; Nzeka, U.; Taylor, J. Nigeria Grain and Feed Annual. In Global Agriculture Information Network; USDA Foreign Agricultural Service: Washington, DC, USA, 2017. 
72. Sani, Y.A.; Jaliya, M.M.; Makeri, M.U.; Sunusi, I.S.I.; Yari, A.A. Sorghum: Production, Processing, Marketing and Utilization. 2013. Available online: https://www.academia.edu/3617293/Sorghum_Production_ Processing_Marketing_and_Utilization (accessed on 15 May 2014).

73. Smith, C.W.; Frederiksen, R.A. Sorghum: Origin, History, Technology, and Production; John Wiley \& Sons: New York, NY, USA, 2000.

74. Mishra, A.; Hansen, J.W.; Dingkuhn, M.; Baron, C.; Traoré, S.B.; Ndiaye, O.; Ward, M.N. Sorghum Yield Prediction from Seasonal Rainfall Forecasts in Burkina Faso. Agric. For. Meteorol. 2008, 148, 1798-1814. [CrossRef]

75. Sasakawa Africa Association. Burkina Faso. Available online: http://www.saa-safe.org/www/burkinafaso (accessed on 1 February 2016).

76. FEWS NET. Burkina Faso Food Security Update. Available online: http://www.fews.net/sites/default/ files/documents/reports/Burkina_Faso_11_2008_Final_en.pdf (accessed on 15 December 2015).

77. Gleisberg-Gerber, K. Livelihoods and Land Management in the Ioba Province in South-Western Burkina Faso; ZEF Working Paper Series 91; University of Bonn: Bonn, Germany, 2012.

78. Some, L.; Dembele, Y.; Ouedraogo, M.; Some, B.M.; Kambire, F.L.; Sangare, S. Analysis of Crop Water Use and Soil Water Balance in Burkina Faso Using CROPWAT; CEEPA Discussion Paper 36; University of Pretoria: Pretoria, South Africa, 2006.

79. Mainardi, S. Cropland Use, Yields, and Droughts: Spatial Data Modeling for Burkina Faso and Niger. Agric Econ. 2011, 42, 17-33. [CrossRef]

80. Nkwake, A.; Magistro, J.; Horjus, P. Building Livelihoods on the Frontlines of Climate Change: Identifying Market Opportunities and Agricultural Value Chains in the Sahel Regions of Niger, Burkina Faso and Mali; Catholic Relief Services: Baltimore, MD, USA, 2014.

81. Bezançon, G.; Pham, J.L.; Deu, M.; Vigouroux, Y.; Sagnard, F.; Mariac, C.; Kapran, I.; Mamadou, A.; Gérard, B.; Ndjeunga, J.; et al. Changes in the Diversity and Geographic Distribution of Cultivated Millet (Pennisetum glaucum (L.) R. Br.) and Sorghum (Sorghum bicolor (L.) Moench) Varieties in Niger between 1976 and 2003. Genet. Resour. Crop Evol. 2009, 56, 223-236. [CrossRef]

82. Omoro, W. Factors for Low Sorghum Production: A Case Study of Small-Scale Farmers in East Kano Sublocation, Nyando District, Kenya; Van Hall Larenstein University of Applied Sciences: Leeuwarden, The Netherlands, 2013.

83. Tack, J.; Lingenfelser, J.; Jagadish, S.K. Disaggregating Sorghum Yield Reductions under Warming Scenarios Exposes Narrow Genetic Diversity in US Breeding Programs. Proc. Natl. Acad. Sci. USA 2017, 114, 92296-92301. [CrossRef]

84. Vanya, C.L. Impact of Climate Variability and Change on Sorghum Production in the Lower Shire Valley in Malawi. Ph.D. Thesis, University of Nairobi, Nairobi, Kenya, May 2012. 